\title{
RFID Applications: Prospects and Challenges in Bangladesh
}

\author{
Abdul Kadar Muhammad Masum, Faruk Bhuiyan, Kazi Golam Azam \\ Department of Business Administration, International Islamic University, Chittagong, Bangladesh \\ Email: akmmasum@yahoo.com, farukbhn84@gmail.com,mdkg_azam.iiuc@yahoo.com
}

Received September 8, 2012; revised October 1, 2012; accepted October 23, 2012

Copyright (c) 2013 Abdul Kadar Muhammad Masum et al. This is an open access article distributed under the Creative Commons Attribution License, which permits unrestricted use, distribution, and reproduction in any medium, provided the original work is properly cited.

\begin{abstract}
Radio frequency identification (RFID) is an emerging technology, radio wave communication between a microchip and an electronic reader, consisting of data gathering, distribution, and management systems that has the ability to identify or scan information for remoting recognition of objects with increased speed and accuracy. An attempt has been made to know how using of RFID technology helps to improve services and business process efficiency in public and private sectors of Bangladesh. With this aim, we have conducted extensive literature survey. At the end of this attempt, we have come to the conclusion that the potential use of this technology includes RFID chipped passports, human implants, item-level tagging, inventory tracking and access control systems. RFID technology is at its early stage of adoption in Bangladesh with a few business applications and pilot studies. However, when tags begin to be associated with individuals, privacy is threatened. RFID is a new type of threat to personal information and must be treated as such; indeed, it must be recognized that existing privacy legislation is not adequate. This paper also explores some current and emerging applications of RFID in Bangladesh and examines the challenges including privacy and ethical issues arising from its use, as well as addressing potential means of handling those issues.
\end{abstract}

Keywords: RFID (Radio Frequency Identification); Potential Applications; Challenges; Bangladesh

\section{Introduction}

RFID is not a new technology despite rapidly growing interest in RFID technology in recent years. The concept of the technology dates to the mid to late 1940s, following on from technological developments in the 1930s and the development of radar during World War II [1]. In the 1950s, several technologies related to RFID technology were developed. Technological innovations and their consequences are becoming indispensable parts of our daily lives. RFID, as one of these innovations, is a system that provides easy, secure and quick data entry, storage and transmission. It is used in many places such as shops, stores, hospitals, pharmaceuticals companies, logistic services etc. where real time data should be used. It is important in improving efficiency and visibility, cutting costs, delivering better asset utilization, producing higher quality goods, reducing shrinkage and counterfeiting, and increasing sales by reducing out-of-stocks [2]. Most of developed and developing countries are using RFID technology in their private and public sectors.

Although implementing RFID technology is a com- plicated process, the right planning and development of an RFID strategy can offer important advantages to business systems and public sectors. While RFID technology has received a fair amount of attention in media recently [3], many are still unfamiliar with RFID and the benefits it can offer. In the face of the need for clear, extensive information about RFID and its benefits, this paper presents the opportunities offered by the technology for any organization or any agency of Bangladesh government involved in the production, management, and sale of goods or services.

In this paper, we motivate our work in Section 2, and the methodology of the research is mentioned in Section 3. Related previous study of RFID Technology is described in Section 4. Furthermore, we have briefly described the working mechanism of RFID technology and its characteristics in Sections 5 and 6. Besides, Section 7 includes RFID applications in present world. Implication of RFID Technology and its possible applications for Bangladesh are explored in Sections 8 and 9. Moreover, Considerable issues and some suggestions to implemen- 
tation of RFID technology in Bangladesh are given Sections 10 and 11.

\section{Objectives of the Study}

In this study, an attempt has been made to know how using of RFID technology helps to improve services and business process efficiency in public and private sectors of Bangladesh. However, the specific objectives of the study are set forth as below:

a) To delineate the concise essentials of RFID technology;

b) To explore its current and emerging applications in present world with especial reference of Bangladesh;

c) To evaluate the challenges to implement RFID technology in Bangladesh;

d) To provide some recommendation for prevail over those challenges.

\section{Methodology of the Study}

In light of the objectives of the study, the paper has been designed to investigate how using of RFID technology enhance the efficiency of services and business processes in public and private sector of Bangladesh. To this end an extensive literature survey has been conducted. The study is based largely on secondary data. Data and information from secondary sources were collected by reviewing different published articles, online journals, working papers, existing case studies and websites.

\section{Literature Review}

Radio frequency identification (RFID) technology is currently one of the technological most promising and discussed auto-identification and data capture (AIDC) technologies [4]. It is not actually a new technology, but it is being applied in new ways, spurred by technological advances and decreased costs. Once used during World War II to identify friendly aircraft, RFID is now being used in a variety of public and private sectors setting from hospital to the highway [5]. A number of studies show that it can be used in many different ways to create value. That is why, several world largest companies use RFID technology to boost up the business performance with great care of consumers and environmental concerns. Chao-Che Lin and Teh-Hsing Ku demonstrates how participating employees with a systemic view can adopt a better methodology to solve problems in RFID and how performance can be enhanced through Systems Thinking [6]. A workshop report was presented from the staff of US federal commission in March, 2005. The workshop brought together RFID proponents, privacy experts, and other interested parties to discuss RFID's various current and potential applications and their implications for con- sumer privacy. It also highlighted proposals to address these implications and generated discussion about the merits of these different approaches [7]. Another study conducted by Mehmet Barut, Bobert Brown, Nicole Freund, Jonathan may, and Elizabeth Reinhart proposed to add comprehensive ethical and investment deliberation as a means to explore the true value of RFID and its applications [8]. The first exhaustive empirical analysis of performance measurement behavior in the RFID field conducted by to measure the economic performance of their applications and how is the success of RFID applications affected by performance measurement. Nemeth et al. [9] present a state-of-the-art on RFID systems and the challenges and possibilities of the integration to supply chains. Chao et al. [10] review the literature on trends and forecast of RFID technologies from 1991 to 2005 by a historical review method and bibliometric analyze. They focus on the RFID innovation, deployment by enterprises and market diffusion in supply chain management. Recently, Delaunay et al. [11] present a survey on the causes of inventory inaccuracy in supply chain management. Dolgui and Proth [12] also present a literature review on RFID technology in supply chain. They focus on the advantages of RFID technologies in inventory management. They also analyze some problems and present perspectives dealing with privacy and authentication properties of RFID technologies. In Bangladesh, Apollo Hospitals, Dhaka and Bangladesh Army are the early adopters of RFID technology.

\section{RFID (Radio Frequency Identification Device)}

RFID has come to signify system solutions for tracking and tracing objects both globally and locally using RFID tags. RFID is one of several technologies collectively known as auto-ID procedures-procedures for identifying objects automatically [13]. RFID by itself is not a location-tracking technology. At sites where readers are installed, RFID may be used to track tagged objects, but this static readability differs from technology such as global positioning systems, or GPS, which uses a network of satellites to pinpoint the location of a receiver [14]. The effectiveness of an RFID application in addressing desired functionality depends on several important factors:

Contactless: An RFID tag can be read without any physical contact between the tag and the reader.

Writable Data: The data of a read-write (RW) RFID tag can be rewritten several times.

Absence of Line-of-Sight: A line of sight is generally not required for an RFID reader to read a tag.

Variety of Reading Ranges: An RFID tag can have a reading range from as small as a few inches to as large as 
more than 100 feet.

Wide Data-Capacity Range: A tag can store from a few bytes of data to virtually any amount of data.

Support for Multiple Tag Readings: It is possible to use an RFID reader to automatically read several RFID tags in its reading zone within a short period of time.

Durable: RFID tags and readers can easily operate under difficult conditions.

Perform Smart Tasks: In addition to the tasks of carrying and transmitting of data, an RFID system can be designed to perform some other tasks (e.g., acculturation to environmental conditions, operating at high or low temperature and pressure).

Extreme Reading Accuracy: Tanks to extreme reading accuracy advantage, RFID is an accurate and secure technology for data gathering and management.

The advantages listed above are generic for any type of RFID systems. Some additional factors such as privacy and security concerns, data mining, and the integration of the RFID with other technologies such as biometric systems, Global Positioning Systems (GPS) and wireless communication technologies are needed to be considered for applications [15].

\section{How Does RFID Work?}

RFID devices have three primary elements: a chip, an antenna, and a reader. A fourth important part of any RFID system is the database where information about tagged objects is stored. The chip contains information about the item to which it is attached. Chips used by retailers and manufacturers to identify consumer goods may contain an Electronic Product Code ("EPC") [16]. EPC chips are encrypted with a unique product code that identifies the individual product to which it is attached, and can be read using radio frequency. The antenna attached to the chip is responsible for transmitting information from the chip to the reader, using radio waves. The chip and antenna combination is referred to as a transponder or, more commonly, as a tag. The reader, or scanning device, also has its own antenna, which it uses to communicate with the tag [17]. RFID systems can employ authentication and encryption to prevent unauthorized reading of data [18]. "Reading" tags refers to the communication between the tag and reader via radio waves operating at a certain frequency. A stationary reader that could be used to track tagged cases of goods entering a warehouse a mobile reader used to monitor inventory on a retail store floor and a prototype of a glove embedded with a scanner used to track daily domestic living activities, a reader communicates with a tag in order to capture the data stored in the tag. The reader usually sends a low-power radio signal to activate the tag and the tag then sends data back to the reader. Most readers are-as their names suggest—only capable of reading data, although some also have the capability to write to certain tags. Normally, readers forward the data to other systems (such as PCs) for subsequent processing. In comparison to tags, readers consume more power, are larger and more expensive. RFID systems use radiosignals to communicate, but only certain frequency bands are available for license-free use. There is international variation in the frequencies and power levels available for RFID systems. Due to different national regulations, an RFID system produced in one country may not work in another country. The database, or other back-end logistics system, stores information about RFID-tagged objects. Access to both a reader and its corresponding database are necessary before information stored on an RFID tag can be obtained and understood.

There are two types of tags, namely active and passive tags. Active tags are larger, heavier and more expensive than passive ones as they contain their own power source (battery). Nevertheless, they emit stronger signal, operating normally at higher frequencies $(455 \mathrm{MHz}-950$ MHz or 2.45 - $5.8 \mathrm{GHz}$ ) capable of being captured by the reader over a longer distance measuring 20 - 100 meters. The tags are more suitable for tracking valuable items. On the hand, passive tags are much smaller, lighter and cheaper than active tags. Typically it is operating at lower frequencies ( $30 \mathrm{kHz}-134 \mathrm{KHz}$ or $13.6 \mathrm{MHz}$ ) with a capture range of between several centimeters and 10 meters. They are commonly used for asset tracking and security applications.

\section{Present Scenario of RFID Applications in World}

According to the European e-Business Watch large-scale survey [19] of RFID adoption strategies and impacts in four broad economic sectors, $14 \%$ of the European companies interviewed were piloting, using or implementing RFID technology in 2007. Companies that were using RFID or planning to use RFID expected major effects on: a) inventory management (49\% of companies using or planning to use RFID), b) control and efficiency of inbound logistics (46\%), and c) merchandise management and reduced out-of-stocks (44\%). The major costs for those using or planning to use the technology were seen to be the costs of project implementation and system integration (39\% of all companies using or planning to use RFID). Interestingly, for those companies not using or planning to use RFID technology, 64\% stated that a relevant reason for not using it was the insufficient evidence of a strong return on investment (ROI). Wal-Mart and the Department of Defense (DOD) of US told their top suppliers to begin tagging cases and pallets with RFID tags by January of 2005. Indeed, Gartner antici- 
pates that by 2012 most "enterprises will be forced to redesign their value chain processes as a result of RFID changing the storage, collection, and use of data concerning goods in the supply chain”. If predictions are true, then the RFID market will approach \$4 billion by 2012 [15]. Selected RFID applications in the public sector in some countries are given below:

Health Sector: Austria tests by the municipal administration of Vienna on the applicability of RFID in the health care system. Mexico has Health insurance card: RFID technology is integrated in the "popular insurance" card where the username, information on doctors as well as prescribed drugs are stored. Korea uses RFID technology in hospitals.

e-Passport: In Denmark, e-passport is available since mid-2006; biometric passport relying on RFID embedded fingerprint technology is introduced mid-2009. Germany has introduced e-passport since the end of 2005 and electronic ID card since the end of 2009. Biometric passport is relying on RFID technology in Netherlands, USA and UK. Portugal has e-passport and e-passport control systems at Portuguese airports.

Public Services: Austria tests in the Viennese parking facility management. Germany uses Waste management in different communities. Korea has implemented Pilot projects in the fields of procurement, baggage handling, container management, ammunition management, tracking hazardous waste, museums etc. RFID tags replace paper season parking tickets at car parks in public housing estates in Singapore.

Education Sector: RFID technology is used in Denmark, Germany, Singapore, Netherlands and United States of America implementing for lending systems in libraries.

Logistics/Transport Sector: Japan has set-up of the "Free Mobility Assistance System” based on ubiquitous network technology including RFID tags, to provide information for seamless movement (e.g. transfer routes and transport modes). Netherlands has introduced payment cards for public transport. Singapore establishes Nationwide Electronic Road Pricing (ERP) system to control and manage traffic volume; payment of road usage charges. The ERP is applied to all of Singapore's 840,000 vehicles.

\section{Implication of RFID Technology for Bangladesh}

A little area of both the private and public sectors are driving the RFID market in Bangladesh. Deltech Ltd., a global RFID solution provider has already helped several organizations implement RFID [20]. According to Mr. Delwar Hossain, founder of the Deltech, hands-free access control and employee-tracking systems, as well as asset management are the most popular applications businesses are asking for. Appollo Hospital, Dhaka has completed the first phase of an RFID project to track employee attendance as well as assets [20]. The Bangladesh Army also plans to employ this technology to track soldiers and visitors entering its Dhaka Cantonment as well as track retail purchases. In many export sectors of Bangladesh ranging from garments to household and office furniture, large international buyers can get rid of the age old barcode-based product identification systems for RFID tags to reduce product tracking and inventory management costs of the items which will ultimately help the country to be competitive in the world market. US retailers like Target, Wal-Mart, etc. are major buyers of Bangladesh's garment products. Since Wal-Mart has already announced its plans to require majority of their suppliers to implement RFID based tracking systems, the Bangladeshi exporters have no choice rather to implement RFID technology to survive in the world market. Besides Wal-Mart and Target, German retailer Metro and furniture maker IKEA (recently commenced operations in Bangladesh on a limited basis), to name a few among the large number of companies, have already started experimenting with RFID integrated supply chain management systems. This sea change in global integrated supply chain management necessitates a rapid mobilizetion of our government, IT and export industry leaders and experts to devise a uniform RFID strategy for Bangladesh.

\section{Potential RFID Applications for Bangladesh}

Radio frequency identification can be used in many different ways to create value and the number is growing at the fast pace. To structure this range of application, some fields of application, which may be suitable for Bangladesh, are given below:

Assets Tracking: RFID can play a vital role to track valuable assets. Companies can put RFID tags on assets that are lost or stolen often, that are underutilized or that are just hard to locate at the time they are needed.

Assets Monitoring and Maintenance: High-value assets can be tagged to store information for maintenance purposes. The tagged machines where the maintenance history and information on replaced parts will be stored on the tag. When data will be stored directly on the tag and not on the companies' network, tags with high data capacity will be needed.

Manufacturing: There is an emphasis on using RFID for applications that can track items from the manufacturing point all the way through to the store shelf. This process entails tagging pallets, cartons, reusable containers and individual items to track the movement of goods throughout the supply chain straight through to the sale 
of the item to the customer. RFID may be used to help automate the processing the incoming shipments of pistachios from grower partners.

Theft Control: Item level RFID tags may be used to prevent theft along the supply chain or at the point of sale. A simple form is electronic article surveillance (EAS) which can be RFID-based. In this case, low-end RFID systems (e.g. 1-bit tags) will be used which communicate when consumers leave the shop if they have not been deactivated. Applications for theft control in mail order for high-value products such as mobile phones use more sophisticated tags.

Authentication: For authentication purposes, RFID may be used to provide secure identification mechanisms for persons and objects. e-passports combine the traditional paper document with an RFID tag where the critical information is stored. The RFID tag often contains biometric data such as data for facial recognition and fingerprints.

Security and Access Control: RFID may be used as an electronic key to control who has access to office buildings or areas within office buildings. It is convenient (an employee can hold up a badge to unlock a door, rather than looking for a key or swiping a magnetic stripe card) because there is no contact between the card and reader, there is less wear and tear, and therefore less maintenance.

Public Services: Public services include services such as the management of parking facilities and waste management. In waste management RFID may be used for two main purposes: for tracking (hazardous) waste to protect the environment and to allocate costs according to the amount of waste.

Health Service: RFID may be used to track assets such as beds or containers, to identify patients for medication control and to track babies and dementia patients to increase their security. Information such as user name and prescribed drugs are stored on the embedded RFID chip. Hospitals can also plan to deploy RFID to identify patients, call up records, reduce medical errors and improve overall productivity.

Document Administration/Postal Services: RFID technology may be used for the administration of documents. In this field, RFID tags will be attached to documents to improve the location of documents and thus to increase process efficiency and quality. RFID may also be used for postal services in distribution centers to facilitate the sorting of mail items.

Public Transport: RFID may be used by the public sector in the fields of logistics and public transports. One of the most popular uses of RFID may be pay for road tolls without stopping vehicles. RFID is also catching on as a convenient way to pay for bus, subway and train rides. Newer applications are access cards for public transport, RFID-based bus schedules as well as particular location-based services.

\section{Challenges to Implementation RFID Technology in both Public and Private Sectors of Bangladesh}

Utilization of RFID for widespread mass commercial applications has been limited primarily due to challenges arising from several key factors. To assess the overall challenge presented to the organization we propose the use of a simple, "Challenge Assessment Matrix" (CAM) based on Likert-like approach.

Management Commitment: The most significant challenge to implementation is the commitment of management to adopting new technology and having appropriate expectations of RFID capabilities.

Selection of Tag and Tag Reader: Several key factors need to be considered, namely the tag type and size, read distance and other tag reader requirements. Active tags are thicker than the passive ones. Another important feature that should be provided is anti-collision since it allows multiple tags to be read in a single pass.

Cost: Even though the RFID tags are getting cheaper, tag costs are obviously the major variable cost component for RFID, but what about other related cost components? Software, systems integration, process redesign and organizational impacts will be significant and must be part of the business case as well. With the anticipated scale and scope of RFID deployment, tag costs are expected to continue their decline. For RFID implementation, organizations have to analyze Return-on-Investment (ROI) according to their business processes.

Data Management: Most ERP systems and WMS systems are not designed for RFID data capture. The Electronic Product Code occupies a larger data field than the Universal Product Code now in place. New structures for data management should be considered prior to any RFID investment.

International Standards: A key challenge is the continually evolving standards in technology, application, data, conformance, firmware changes, and tracking methods. In addition, different companies often use different standards making cooperation between suppliers and manufacturers difficult.

Availability of Resources: The shortage of existing skilled resources and lack of comprehensive, accessible information has cost implications for training and presents potential implementation problems.

Security: For certain implementations, illicit tracking of RFID tags presents problems. This is particularly relevant for military installations but security challenges are relevant also for corporations and individuals. For example, scanning and cloning of RFID tags can potentially provide undesired access to important facilities or use for payment in commercial transactions. 
Business Process Changes: Process automation through RFID will require new work methods and performance measurements for the supply chain. The design of any RFID strategy must consider new processes and procedures to automate tasks and decision making where possible, as well as consider organizational changes.

Ethical Problems: The privacy concern of Bangladeshi consumers is information. The concern of information privacy is the tracking the purchasing habits and other information regarding a particular consumer. This information may be used for targeted advertising or possibly used in evaluating a consumer for various programs such as credit worthiness.

Government Regulations: Implementations are complicated by varying specifications and regulatory requirements, for example operational frequencies and power specifications vary from country to country.

\section{Recommendations for Prevail over Those Challenges}

Bangladesh is always among the last few countries to start using any technology that is already in use for several years in the other developed countries. The primary reasons are the lack of know-how and risk of investment in a new technology. Here, we have provided some suggestions to implement RFID in public and private sectors of Bangladesh.

a) Invest in pilot tests to determine the capabilities and limitations of the software and hardware, as well as the true costs and benefits of RFID. Update the business case based upon the findings.

b) Do not underestimate the need to change business processes to achieve the automation and asset visibility that RFID can provide.

c) At this moment the RFID initiative is discrete in Bangladesh and do not have any long-term strategy leading into implementation-to-diffusion process. Without having a clear strategy to achieve large scale diffusion discrete RFID adoption may not inspire the process in reaching the full potential of RFID.

d) Begin an RFID education effort with a dedicated team that is chartered to recommend and follow a course of action. Research the standards development underway to ensure that the technologies under consideration will meet both domestic and global standards.

e) Businesses must be candid with consumers about the how RFID technology is used in the products which consumers purchase.

f) Consumers should be informed of the existence and location of RFID tag in any product sold. Optimally under these guidelines consumers would have the option of having the devices deactivated at the time of purchase.

g) Ensure that the RFID technology does not interfere with the privacy concerns of consumers is for stores to automatically deactivate RFID tags at point of purchase. RFID tags can be killed in a number of ways; tags designed with a kill switch built in so that upon receiving an instruction they deactivate themselves permanently.

h) Consumer education is a vital part of protecting consumer privacy. Industry members, privacy advocates, and government should develop education tools that inform consumers about RFID technology, how they can expect to encounter it, and what choices they have with respect to its usage in particular situations.

i) Many of the potential privacy issues associated with RFID are inextricably linked to database security. As in other contexts in which personal information is collected from consumers, a company that uses RFID to collect such information must implement reasonable and appropriate measures to protect that data.

j) Government should regulate the use of RFID tags in consumer goods. Optimally a law would require that RFID tags be permanently disabled at the time of purchase. The state would have in the usefulness of RFID tags in public activates such as law enforcement, it is unlikely that the government will be quick to set controls on how these devices are used.

k) Govern should design of an Auto-ID strategy for Bangladesh with a focus upon how business processes and the customer experience can be improved.

\section{Conclusion}

Despite the hype, the promise of RFID technology is real, and can provide increased asset visibility, enhanced information content and velocity. Equally as real are the pitfalls of RFID including cost, competing standards, technology limitations and privacy concerns. The transition to RFID may not occur overnight, but this technology has been given a jump start by leading industries in Europe. Bangladesh can adopt any suitable model for its overall automation in public and private sectors. Anticipate that return on investment for RFID will be low or non-existent initially, but that future gains are possible by redesigning business processes. We recommend RFID education for Bangladeshi consumers and development of the business case and pilot to size the potential benefits and adoption efforts. Finally, we recommend the design of an Auto-ID strategy for Bangladesh with a focus upon how business processes and the customer experience can be improved.

\section{REFERENCES}

[1] Danish Board of Technology, "RFID from Production to Consumption-Risks and Opportunities from RFID Technology in the Value Chain,” 2006. www.tekno.dk/pdf/projekter/p06_rapport_RFID.pdf 
[2] C. C. Chao, J. M. Yang and W. Y. Jen, "Determining Technology Trends and Forecasts of RFID by a Historical Review and Bibliometric Analysis from 1991 to 2005,” Technovation, Vol. 27, No. 5, 2007, pp. 268-279. doi:10.1016/i.technovation.2006.09.003

[3] OECD, "RFID Implementation in Germany: Challenges and Benefits," 2007. www.oecd.org/dataoecd/19/23/39693586.pdf

[4] M. Martin, “The History of RFID Technology,” RFID Journal, 2007.

http://www.rfidjournal.com/article/articleview/1338/1/12 9/

[5] C. Delaunay, E. Sahin and Y. Dallery, “A Literature Review on Investigations Dealing with Inventory Management with Data Inaccuracies in RFID Eurasia, 1st Annual,” 2007, pp. 1-7.

[6] W. Minli, W. Gang and H. Dajun, "Device Management in RFID Public Service Platform," 3rd International Conference on Convergence and Hybrid Information Technology, Busan, Vol. 1, 2008, pp. 1133-1136.

[7] Y. Choi, D. Kang, H. Chae and K. Kim, “An Enterprise Architecture Framework for Collaboration of Virtual Enterprise Chains," The International Journal of Advanced Manufacturing Technology, Vol. 35, No. 11-12, 2008, pp. 1065-1078. doi:10.1007/s00170-006-0789-7

[8] T. Phillips, T. Karygiannis and R. Kuhn, "Security Standards for the RFID Market," IEEE Security and Privacy, 2005, pp. 85-88.

[9] A. Dolgui and J. M. Proth, "RFID Technology in Supply Chain Managment: State of the Art and Perspectives," 17th World Congress the International Federation of Automatic Control, Seoul, 2008, pp. 4465-4475.

[10] A. Sarac, N. Absi and S. Dauzere-Peres, "A Literature Review on the Impact of RFID Technologies on Supply Chain Management," International Journal of Production Economics, Vol. 128, No. 1, 2010, pp. 77-95. doi:10.1016/j.ijpe.2010.07.039

[11] S. Veronneau and J. Roy, "RFID Benefits, Costs, and
Possibilities: The Economical Analysis of RFID Deployment in a Cruise Corporation Global Service Supply Chain,” International Journal of Production Economics, Vol. 122, No. 2, 2009, pp. 692-702. doi:10.1016/j.ijpe.2009.06.038

[12] V. D. Hunt, A. Puglia and M. Puglia, "RFID: A Guide to Radio Frequency Identification,” John Wiley \& Sons Inc., New Jersey, 2007. doi:10.1002/0470112255

[13] Y. Xiao, S. Yu, K. Wu, Q. Ni, C. Janecek and J. Nordstad, "Radio Frequency Identification: Technologies, Applications," Wireless Communications and Mobile Computing, Vol. 7, No. 4, 2007, pp. 45-472. doi:10.1002/wcm.365

[14] B. Bacheldor, "RFID Takes Root in Bangladesh," RFID Journal, 2008.

[15] P. Nmeth, L. Toth and T. Hartvanyi, “Adapting RFID in Supply Chains,” 3rd International Conference on Mechatronics, 2006, pp. 263-266.

[16] M. A. Khan, M. Sharma and R. B. Prabhu, "A Survey of RFID Tags," International Journal of Recent Trends in Engineering, Vol. 1, No. 4, 2007, pp. 68-71.

[17] Y. Choi, D. Kang, H. Chae and K. Kim, “An Enterprise Architecture Framework for Collaboration of Virtual Enterprise Chains," The International Journal of Advanced Manufacturing Technology, Vol. 35, No. 11-12, 2008, pp. 1065-1078. doi:10.1007/s00170-006-0789-7

[18] M. Ohkubo, K. Suzuki and S. Kinoshita, "RFID Privacy Issues and Technical Challenges,” Communications of the ACM, Vol. 48, No. 9, 2005, pp. 66-71. doi:10.1145/1081992.1082022

[19] M. L. Chuang and W. H. Shaw, "RFID: Integration Stages in Supply Chain Management," IEEE Engineering Management Review, Vol. 35, No. 2, 2007, pp. 80-87. doi:10.1109/EMR.2007.899757

[20] S. B. Miles, S. E. Sarma and J. R. Williams, "RFID Technology and Applications,” Cambridge University Press, Cambridge, 2008. doi:10.1017/CBO9780511541155 